\title{
Late outcomes after the Cox maze IV procedure for atrial fibrillation
}

\author{
Matthew C. Henn, MD, Timothy S. Lancaster, MD, Jacob R. Miller, MD, Laurie A. Sinn, RN, BSN, \\ Richard B. Schuessler, PhD, Marc R. Moon, MD, Spencer J. Melby, MD, Hersh S. Maniar, MD, and \\ Ralph J. Damiano, Jr, MD
}

\begin{abstract}
Objective: The Cox maze IV procedure (CMPIV) has been established as the gold standard for surgical ablation; however, late outcomes using current consensus definitions of treatment failure have not been well described. To compare to reported outcomes of catheter-based ablation, we report our institutional outcomes of patients who underwent a left-sided or biatrial CMPIV at 5 years of follow-up.
\end{abstract}

Methods: Between January 2002 and September 2014, data were collected prospectively on 576 patients with AF who underwent a CMPIV $(n=532)$ or left-sided CMPIV $(\mathrm{n}=44)$. Perioperative variables and long-term freedom from $\mathrm{AF}$, with and without AADs, were compared in multiple subgroups.

Results: Follow-up at any time point was $89 \%$. At 5 years, overall freedom from AF was 93 of $119(78 \%)$, and freedom from AF off AADs was 77 of $177(66 \%)$. No differences were found in freedom from AF, with or without AADs, at 1, 2, 3, 4 , and 5 years for patients with paroxysmal AF $(\mathrm{n}=204)$ versus with persistent/ longstanding persistent AF $(n=305)$, or for those who underwent standalone versus a concomitant CMP. Duration of preoperative AF and hospital length of stay were the best predictors of failure at 5 years.

Conclusions: The outcomes of the CMPIV remain good at late follow-up. The type of preoperative AF or the addition of a concomitant procedure did not affect late success. The results of the CMPIV remain superior to those reported for catheter ablation and other forms of surgical AF ablation, especially for patients with persistent or longstanding AF. (J Thorac Cardiovasc Surg 2015;150:1168-78)

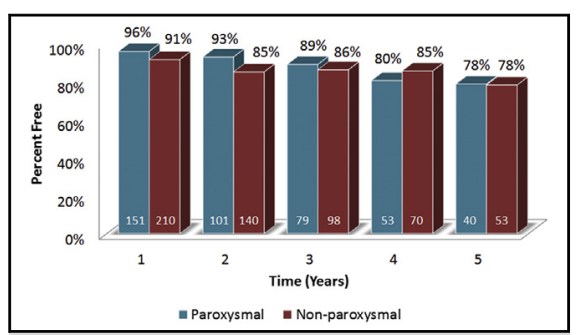

Freedom from atrial tachyarrhythmias was equivalent in those with paroxysmal versus nonparoxysmal atrial fibrillation.

\section{Central Message}

At 5 years, sinus rhythm was restored in most patients after a CMPIV, regardless of AF type. The duration of $\mathrm{AF}$ predicted failure.

\section{Perspective}

The CMPIV remains the most successful surgical treatment for AF, even in patients with nonparoxysmal $\mathrm{AF}$, and regardless of the complexity of the concomitant procedures. Preoperative $\mathrm{AF}$ duration predicted failure at 5 years and suggests the need for earlier intervention.

See Editorial Commentary page 1179.
丹 Supplemental material is available online.

The first effective surgical treatment for atrial fibrillation (AF), now formally known as the Cox maze procedure (CMP), was introduced by James Cox, MD, in 1987. ${ }^{1}$ On

From the Division of Cardiothoracic Surgery, Washington University School of Medicine, Barnes-Jewish Hospital, St Louis, Mo.

This work was supported by the National Institutes of Health, grants R01 HL032257 and T32 HL007776.

Read at the 95th Annual Meeting of The American Association for Thoracic Surgery, Seattle, Washington, April 25-29, 2015.

Received for publication April 21, 2015; revisions received July 8, 2015; accepted for publication July 22, 2015; available ahead of print Sept 30, 2015.

Address for reprints: Ralph J. Damiano, Jr, MD, Division of Cardiothoracic Surgery, Washington University School of Medicine, Barnes-Jewish Hospital, 660 S. Euclid Ave, Campus Box 8234, St Louis, MO 63110 (E-mail: damianor@wustl.edu).

$0022-5223 / \$ 36.00$

Copyright (c) 2015 by The American Association for Thoracic Surgery

http://dx.doi.org/10.1016/j.jtcvs.2015.07.102 the basis of extensive clinical experience and ongoing animal investigations at our institution, substantial revisions of the original "cut-and-sew" technique have led to the current, fourth iteration of the procedure. Introduced clinically in 2002, the Cox maze IV procedure (CMPIV) consists of a combination of bipolar radiofrequency and cryothermal ablation lines that replace most of the surgical incisions of its predecessor (Figure 1). ${ }^{2,3}$

Analysis of early and 1- to 2-year follow-up has demonstrated that the CMPIV provided equivalent rates of freedom from $\mathrm{AF}$ and can be performed with shorter cardiopulmonary bypass and crossclamp times, and with less perioperative morbidity, than the traditional "cut-and-sew" CMPIII. ${ }^{3,4}$ Additionally, we have shown that the procedure is equally effective in patients undergoing ablation for lone $\mathrm{AF}$ and concomitant cardiac surgery, including coronary artery bypass grafting, mitral valve, and aortic valve procedures. $^{5-10}$

The modifications of the CMPIV have allowed it to be performed through a right minithoracotomy approach, 


$$
\begin{aligned}
& \text { Abbreviations and Acronyms } \\
& \qquad \begin{aligned}
\text { AAD } & =\text { antiarrhythmia drugs } \\
\text { AF } & =\text { atrial fibrillation } \\
\text { ATA } & =\text { atrial tachyarrhythmia } \\
\mathrm{CI} & =\text { confidence interval } \\
\mathrm{CMP} & =\text { Cox maze procedure (III and IV) } \\
\mathrm{OR} & =\text { odds ratio } \\
\mathrm{PVD} & =\text { peripheral vascular disease }
\end{aligned}
\end{aligned}
$$

which has further reduced major morbidity, mortality, and hospital stay compared with those who underwent sternotomy while enjoying outcomes with equivalent freedom from $\mathrm{AF}^{11-13}$ Finally, the CMPIV has proven to be effective in patients with both paroxysmal and nonparoxysmal (persistent and longstanding persistent) forms of AF, a quality that distinguishes the CMPIV from other less-extensive lesion sets used for catheter and surgical AF ablation. ${ }^{14-16}$

Although our results to date establish the CMPIV as the current gold standard for surgical AF ablation, late outcomes of AF freedom using current consensus definitions of treatment failure have yet to be confirmed. Recent reports of long-term ( $>5$-year) outcomes after the CMP have demonstrated good results ${ }^{17}$; whereas catheter ablation and pulmonary vein isolation have yielded suboptimal rates of freedom from AF in most patients. ${ }^{16,18-23}$ In this report, we examine our late outcomes of patients undergoing the CMPIV procedure for AF ablation at 5-year follow-up.

\section{METHODS}

The Washington University School of Medicine Institutional Review Board approved this study, and written informed consent was obtained from each patient prior to their enrollment. Over 400 demographic and perioperative variables were prospectively entered into the Society for Thoracic Surgery database or a longitudinal database maintained at our institution.

\section{Patient Population}

Between January 2002 and December 2014, data were collected prospectively on 576 consecutive patients with $\mathrm{AF}$ who underwent a CMPIV $(\mathrm{n}=532)$ or left-sided CMP $(\mathrm{n}=44)$ with or without a concomitant procedure. The operative details of the CMPIV lesion set through a sternotomy or right minithoracotomy have been described previously by our group. ${ }^{4,11-12}$ In 2005 , the CMPIV was modified to include a superior connecting lesion, which formed a "box lesion" by completely isolating the entire posterior left atrium (Figure 1). ${ }^{2,24}$ Prior to 2005, patients underwent the original iteration of the CMPIV lesion set, which lacked a superior left atrial bipolar radiofrequency lesion connecting the right and left superior pulmonary veins. ${ }^{3}$ Of the patients who received a CMPIV, 472 of $532(89 \%)$ had a box lesion, and 40 of $44(90 \%)$ who received a left-sided CMP had a box lesion. Otherwise, patients who underwent a left-sided CMP had a complete CMPIV left atrial lesion set. Preoperative and perioperative variables were retrospectively evaluated and compared.

\section{Follow-up}

Freedom from atrial tachyarrhythmias (ATAs) and from antiarrhythmic drugs (AADs) at 1, 2, 3, 4, and 5 years were evaluated by electrocardiogram or prolonged monitoring by either 24-hour Holter monitoring, pacemaker interrogation, or interrogation of implantable loop recorders, as recommended by consensus guidelines. ${ }^{25}$ Success was defined as freedom from ATAs (AF, atrial flutter, or atrial tachycardia) after a 3-month blanking period, as defined in the expert consensus statements, ${ }^{25}$ and those with subsequent ablations were deemed permanent failures. Patients were discharged on class I or III AADs and warfarin for at least 2 months, unless contraindicated. The AADs were discontinued after 2 months if the patient was in a normal sinus rhythm; anticoagulation was discontinued at 3 months if prolonged monitoring showed no $\mathrm{AF}$, and no evidence of left atrial stasis was found on echocardiography. Calcium channel blockers and $\beta$-blockers were not considered to be AADs.

The average follow-up time was $3.3 \pm 4.7$ years. At 1, 2, 3, 4, and 5 years after surgery, follow-up was 446 of 534 (84\%), 304 of 457 (67\%), 223 of $383(58 \%), 166$ of $300(55 \%)$, and 139 of $241(58 \%)$, respectively. Prolonged continuous monitoring was obtained in 298 of $446(67 \%), 201$ of $305(66 \%), 142$ of $224(63 \%), 95$ of $167(57 \%)$, and 72 of $139(52 \%)$, at $1,2,3,4$, and 5 years, respectively.

\section{Freedom From Atrial Tachyarrhythmias and Antiarrhythmia Drugs}

Late freedom from ATAs and AADs was compared for those who underwent a box lesion set (512 of 576) versus those who did not (64 of 576). Those who did not undergo a box lesion were excluded from the remainder of analyses. In the patients with a box lesion set $(n=512)$, long-term freedom from ATAs and AADs, as well as selected preoperative and perioperative variables, were compared for those patients with paroxysmal AF $(\mathrm{n}=204)$ versus those with persistent or longstanding persistent AF $(\mathrm{n}=305)$. Most patients in both the paroxysmal and nonparoxysmal groups underwent concomitant procedures. Of those who underwent concomitant procedures, 206 of $408(50 \%)$ underwent a concomitant mitral valve procedure with or without a tricuspid procedure, whereas 93 of 408 $(23 \%)$ underwent coronary artery bypass grafting with or without a mitral procedure (Table E1). In addition, late freedom from ATAs and AADs was compared for those who underwent a standalone $(\mathrm{n}=146)$ versus concomitant CMPIV $(\mathrm{n}=366)$.

\section{Statistical Analysis}

Continuous variables were expressed as mean $\pm \mathrm{SD}$ or as median with range; they were compared using the $t$ test for means of normally distributed continuous variables and the Mann-Whitney $U$ nonparametric test for skewed distributions. Categoric variables were expressed as frequencies and percentages, with outcomes compared using $\chi^{2}$ analysis or the Fisher exact test. Twenty preoperative and perioperative variables were evaluated in a univariate analysis, to identify potential predictors of late ATA recurrence or AAD use at 1 and 5 years. Significant covariates on univariate analysis $(P \leq .10)$, or covariates deemed clinically relevant based on our experience, were entered into a multivariate binary logistic regression analysis, and receiver operator curves were constructed. All data analyses were performed using Systat 13 software (Systat Software, Inc, Chicago, Ill).

\section{RESULTS}

\section{Demographics}

The mean overall age was $64 \pm 12$ years, and 351 of 576 $(61 \%)$ of the population were men. Of the overall cohort, 237 of $576(41 \%)$ had paroxysmal AF, and 336 of 576 $(58 \%)$ had nonparoxysmal AF, with 66 of $336(20 \%)$ 


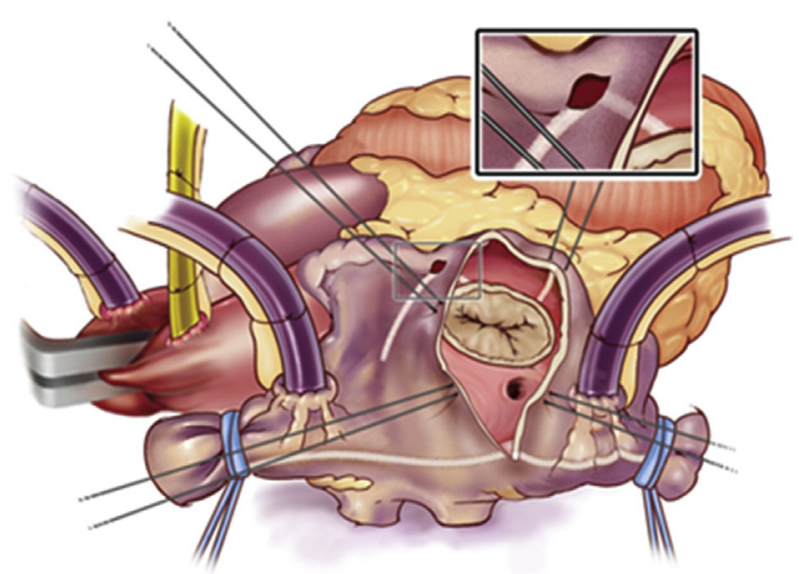

A
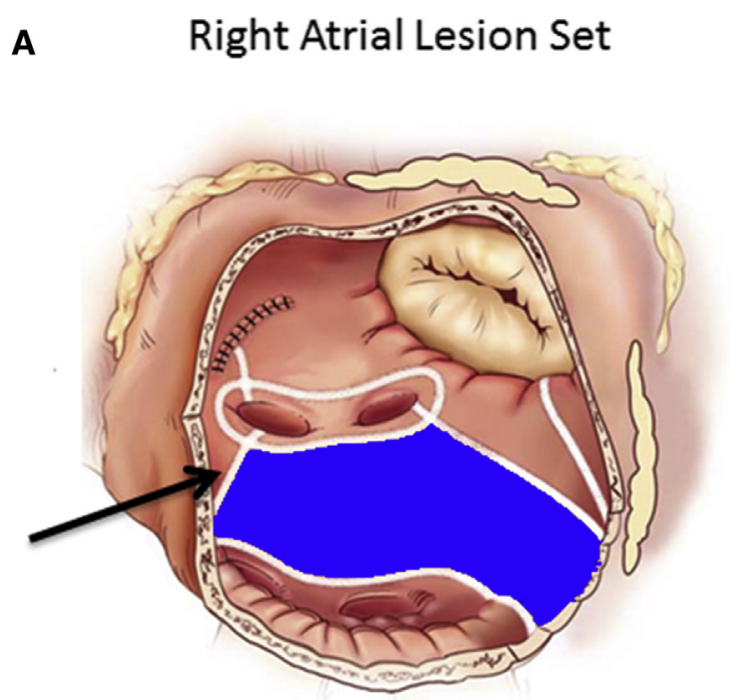

B Left Atrial Lesion Set

FIGURE 1. Standard (A) right and (B) left atrial lesion sets utilized for the CMPIV procedure. In the right atrium (A), radiofrequency ablation lines (white lines) extend from the superior to inferior vena cava, and along the right atrial free wall down to the tricuspid valve annulus. In the left atrium (B), all ablation lines are performed with a bipolar radiofrequency clamp, except for an endocardial cryoablation at the mitral annulus and an epicardial cryoablation over the coronary sinus. Full isolation of the posterior left atrium (blue area) by creating a "box lesion" was accomplished by adding a superior connecting lesion (black arrow) joining the right and left circumferential pulmonary vein ablations. The box lesion was added to the CMPIV lesion set in 2005. ${ }^{24}$ (Figure modified with permission from Weimar and colleagues ${ }^{2}$ ).

having persistent and 270 of $336(80 \%)$ having longstanding persistent AF. Demographic data were compared for those with paroxysmal AF versus those with nonparoxysmal AF (Table E2). Compared with the paroxysmal AF group, the nonparoxysmal AF group of patients had a worse substrate of $\mathrm{AF}$, as indicated by longer duration of preoperative $\mathrm{AF}(6.6 \pm 6.8$ vs $4.9 \pm 7.1$ years, $P=.005)$, larger left atria $(5.3 \pm 1.1$ vs $5.0 \pm 1.1 \mathrm{~cm}, P=.006)$, and more failed catheter ablations (95 of 336 [28\%] vs 22 of 237 [9\%], $P<.001)$.

\section{Perioperative Results}

Most patients underwent sternotomy in both the paroxysmal AF and nonparoxysmal AF groups (182 of 237 [77\%] and 273 of $336[81 \%]$ ), respectively, $P=.113$; Table E3, whereas the remaining patients underwent a right minithoracotomy as previously described. ${ }^{11-13}$ More patients underwent concomitant procedures in the paroxysmal, compared with the nonparoxysmal $\mathrm{AF}$ group (193 of 237 [81\%] vs 212 of 336 [63\%], $P<.001$; Table E3). As expected, no differences were found between the 2 groups in 30-day mortality, postoperative pacemaker implantations, intensive care unit length of stay, hospital length of stay, or most major complications. The paroxysmal group had a slightly higher rate of postoperative pneumonia $(11 \%$ vs $7 \% ; P=.04)$. In the nonparoxysmal group, 293 of $305(96 \%)$ underwent a biatrial CMPIV, compared with 178 of $204(87 \%)$ of the paroxysmal group $(P<.001)$, whereas all others underwent a left-sided CMPIV.

\section{Freedom From Atrial Tachyarrhythmias and Antiarrhythmia Drugs}

In the entire cohort, including both those who did and those who did not undergo box lesion sets $(n=576)$, the overall freedom from ATAs at 1, 2, 3, 4, and 5 years was 411 of $446(92 \%), 267$ of $304(88 \%), 194$ of $223(87 \%)$, 135 of $166(81 \%)$, and 102 of 139 (73\%). Overall freedom from ATAs and AADs for the entire cohort at 1,2,3, 4, and 5 years was 357 of $440(81 \%), 231$ of $298(78 \%), 164$ of $213(77 \%), 110$ of $160(69 \%)$, and 83 of $235(61 \%)$. Freedom from anticoagulation at 1, 2, 3, 4, and 5 years was 286 of $440(65 \%), 184$ of $296(62 \%), 136$ of 213 $(64 \%), 92$ of $161(57 \%)$, and 76 of $138(55 \%)$, respectively.

\section{Lesion Set}

Freedom from ATAs, either with or without taking AADs, was significantly higher in those who underwent box lesion sets, compared with those who did not, at 5 years (93 of 119 [78\%] vs 9 of 20 [45\%], $P=.005$; and 77 of 117 [66\%] vs 6 of 18 [33\%], $P=.017$, respectively; Figure 2, $A$ and $B$ ). No significant difference was found in freedom from ATAs, either with or without taking AADs, between the biatrial CMPIV lesion set and the leftsided CMPIV lesion set at 5 years (95 of 130 [73\%] vs 7 of $9[78 \%], P=.758$, and 78 of $126[62 \%]$ vs 5 of 9 [56\%], $P=.705$, respectively). However, the number of left-sided CMPIV patients was small, making ensuring validity of comparisons difficult. 


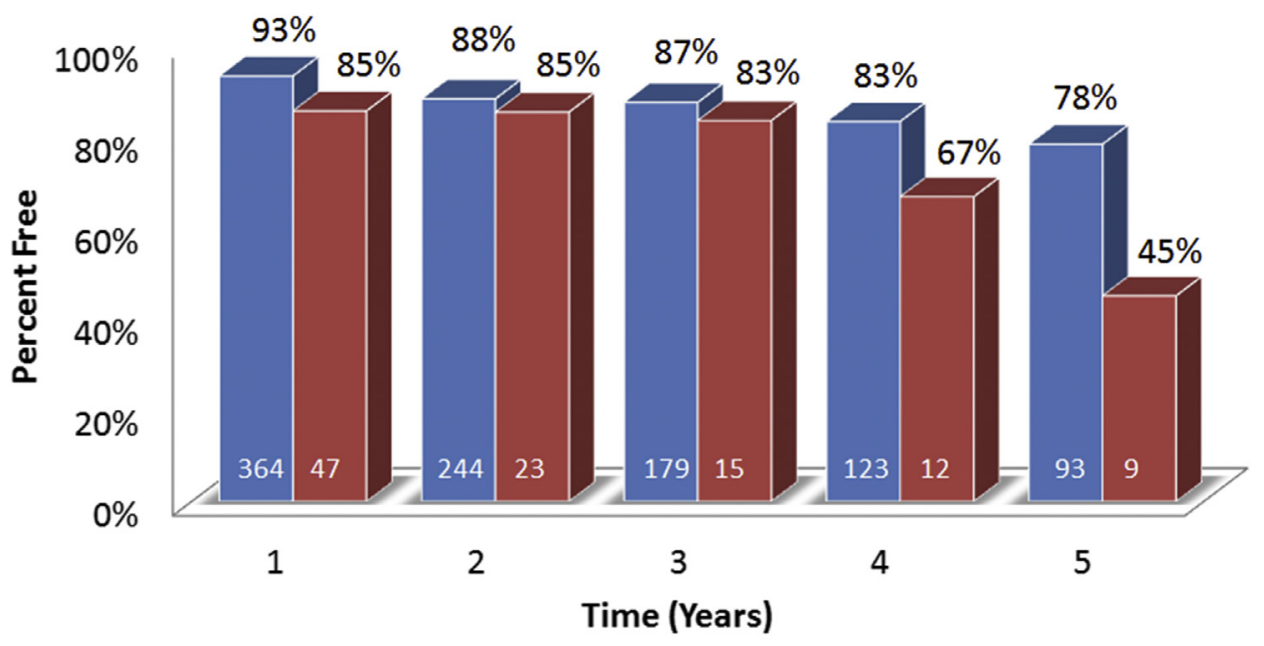

A

With Box Lesion $\quad$ Without Box Lesion

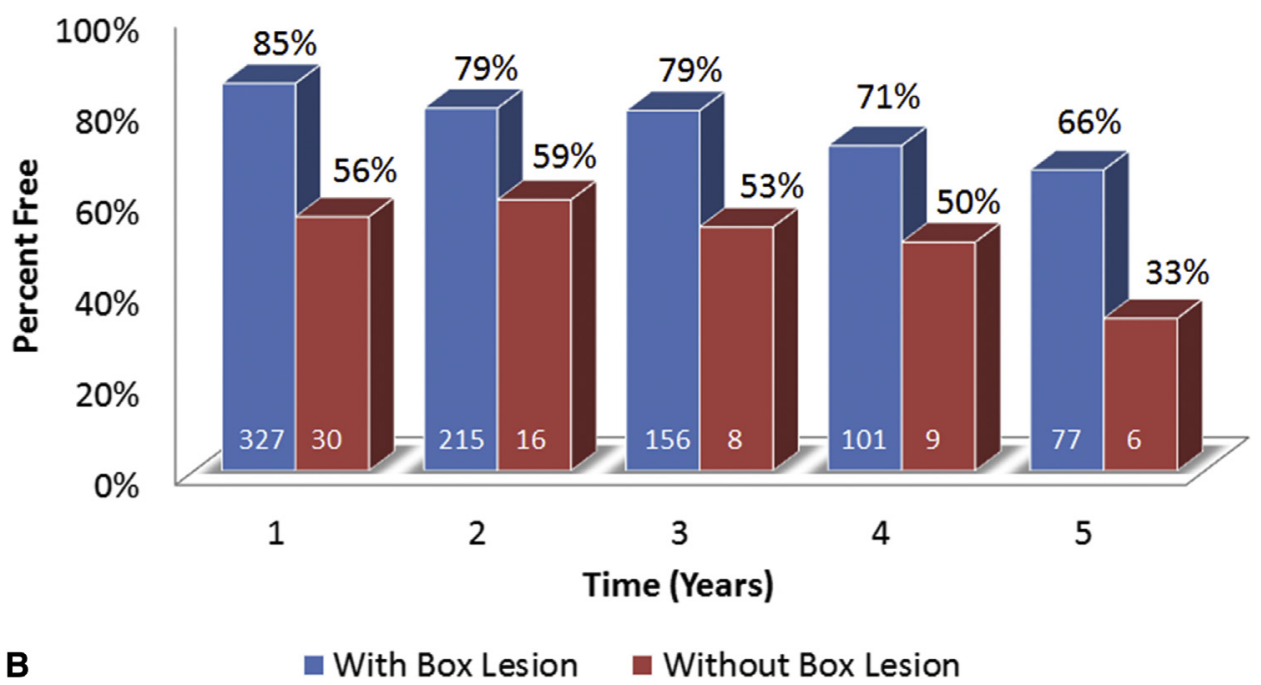

FIGURE 2. Freedom from (A) atrial tachyarrhythmias, and (B) atrial tachyarrhythmias without antiarrhythmia drugs in patients who underwent full posterior left atrial isolation (box lesion) and those who did not.

\section{Paroxysmal Versus Nonparoxysmal Atrial Fibrillation}

With those who did not undergo box lesion sets excluded, freedom from ATAs at 1, 2, 3, 4, and 5 years was not significantly different between those with paroxysmal versus nonparoxysmal AF, which were, respectively, at 1 year, 151 of $158(96 \%)$ versus 210 of $230(91 \%)$, $P=.105$; at 2 years, 101 of $109(93 \%)$ versus 140 of $165(85 \%), P=.051$; at 3 years, 79 of $89(89 \%)$ versus 98 of $114(86 \%), P=.554$; at 4 years, 53 of $66(80 \%)$ versus 70 of $82(85 \%), P=.414$; and at 5 years, 40 of $51(78 \%)$ versus 53 of $68(78 \%), P=.97$, respectively; Figure 3, A.
No significant differences were found in freedom from ATAs, without taking AADs, between the paroxysmal and nonparoxysmal AF groups at any time point (1 year: 137 of 156 [88\%] vs 187 of 227 [82\%], $P=.147 ; 2$ years: 86 of 106 [81\%] vs 126 of $162[78 \%$ ], $P=.509 ; 3$ years: 70 of 86 [81\%] vs 84 of 110 [76\%], $P=.394 ; 4$ years: 42 of 51 [69\%] vs 59 of 81 [73\%], $P=.604$; and 5 years: 33 of 50 [66\%] vs 44 of 67 [66\%], $P=.97$, respectively; Figure $3, B)$. No significant differences were found in freedom from ATAs, with or without taking AADs, at 1, $2,3,4$, and 5 years between those who underwent standalone CMPIV versus concomitant procedures (Figure 4, $A$ and $B)$. 

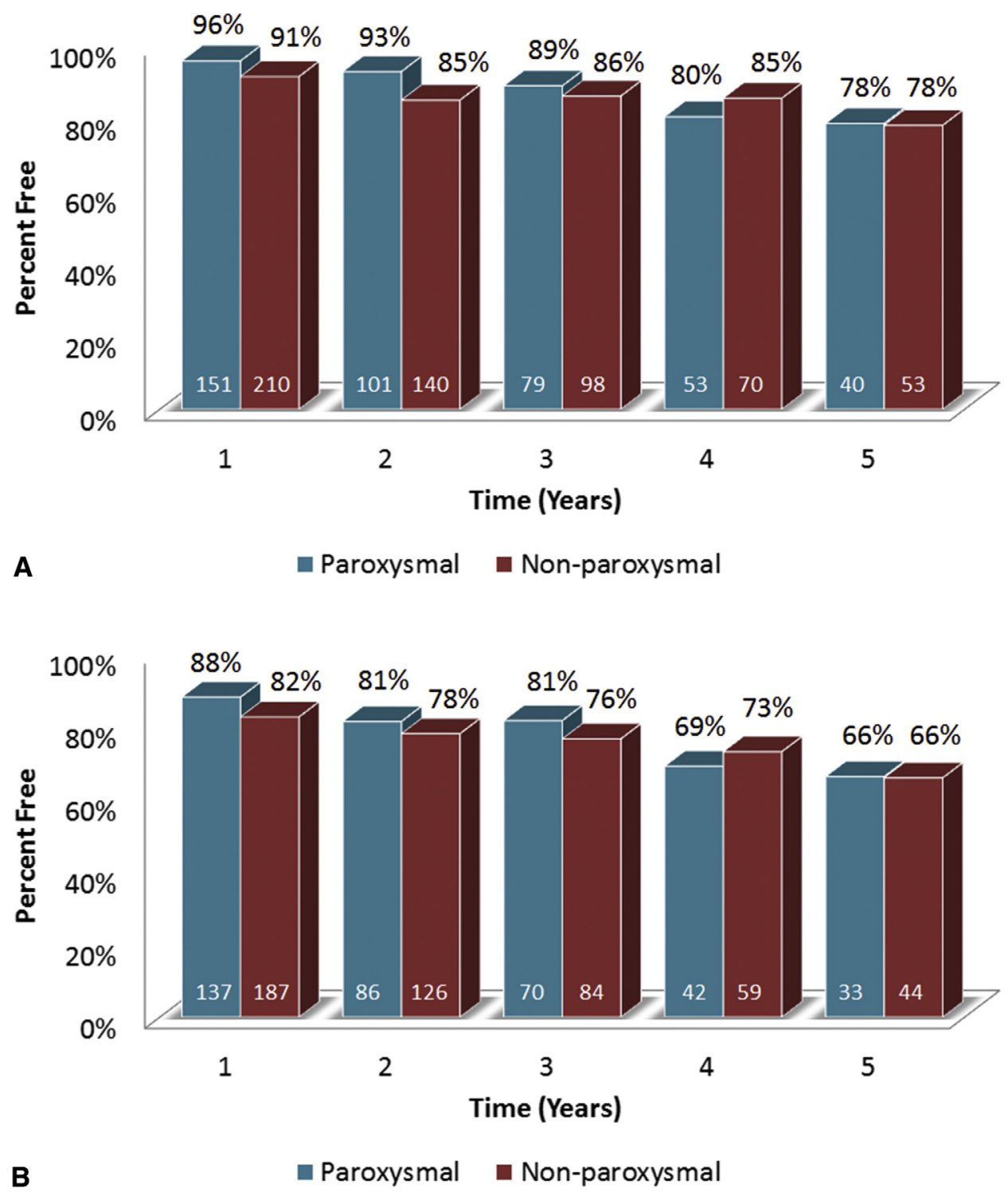

FIGURE 3. Freedom from (A) atrial tachyarrhythmias and (B) atrial tachyarrhythmias without antiarrhythmia drugs in patients with paroxysmal versus nonparoxysmal atrial fibrillation.

\section{Predictors of Recurrence}

Univariate analyses of preoperative and perioperative variables were performed to determine predictors of late ATA recurrence or AAD use at 1 and 5 years. At 1 year, the absence of a box lesion, early ATAs, preoperative pacemaker implantation, and left atrial size were all predictive of recurrence (Table E4). In a multivariable binary logistic regression analysis, a preoperative pacemaker (odds ratio [OR] 2.492, 95\% CI (1.351-4.599), $P=.012$ ), left atrial size (OR $1.285,95 \%$ CI (1.022-1.615), $P=.031)$, and absence of a box lesion set (OR 4.556, 95\% CI (2.364-8.780), $P<.001$ ) were predictive of ATA recurrence or AAD use at 1 year.

In the univariate analyses at 5 years, the absence of a box lesion, early ATAs, the duration of preoperative AF, total intensive care unit time, overall complications, and hospital length of stay were all predictive of failure (Table E4). In the multivariate analysis, the duration of preoperative AF (OR $1.09,95 \%$ CI (1.02-1.16), $P=.008)$ and hospital length of stay (OR 1.09, 95\% CI (1.01-1.17), $P=.026)$ predicted recurrence of ATAs or AAD use at 5 years. The probability of failure increased with increasing duration of preoperative AF (Figure 5).

\section{DISCUSSION}

Over the past 3 decades, the CMP has been the most successful surgical treatment for $\mathrm{AF}^{4,8,26}$ In the current study, 5 -year outcomes of the newest iteration of the Cox maze procedure, the CMPIV, are reported. The primary finding 

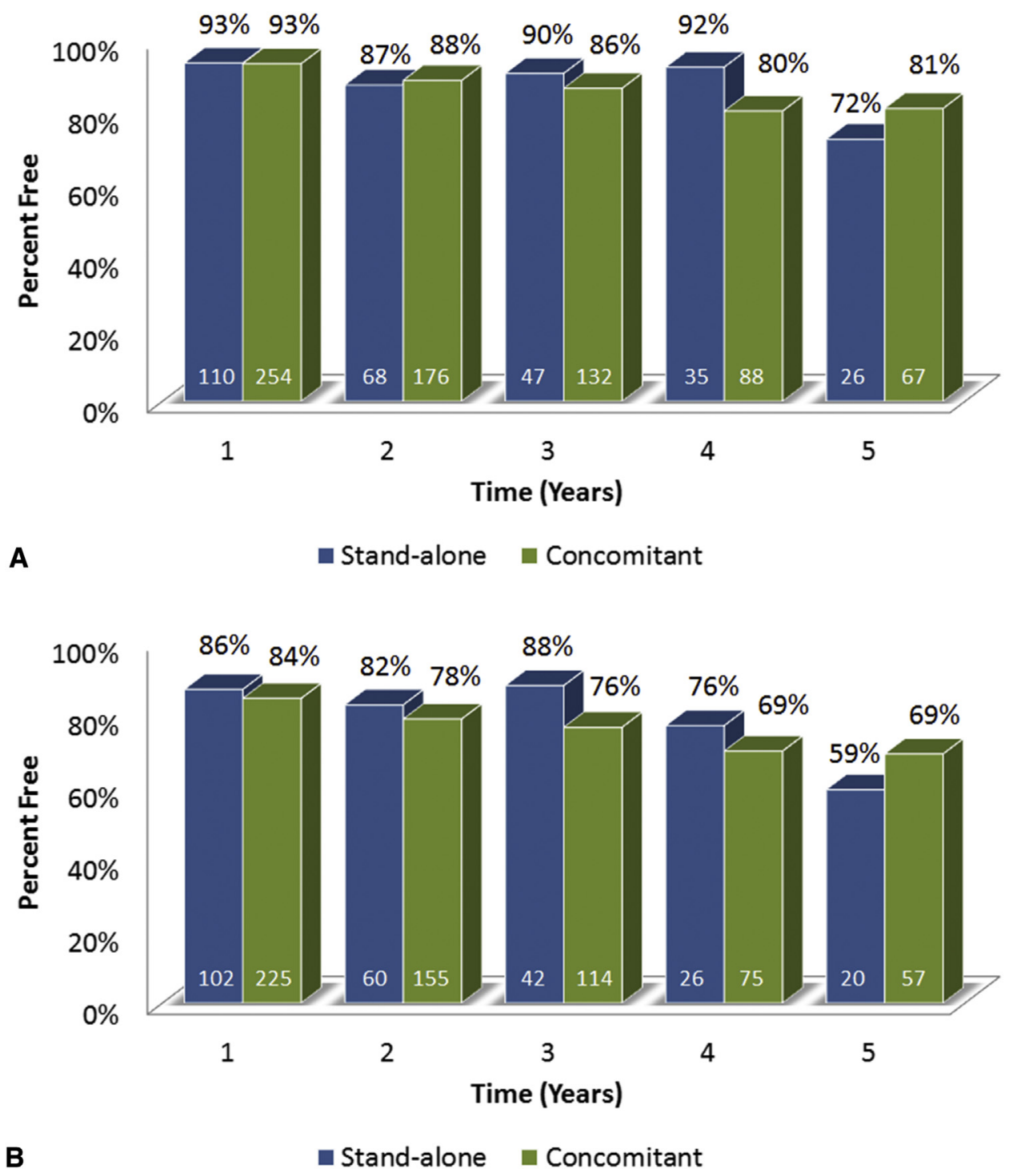

FIGURE 4. Freedom from (A) atrial tachyarrhythmias and (B) atrial tachyarrhythmias without antiarrhythmia drugs in patients who underwent standalone CMPIV versus CMPIV with a concomitant procedure.

is that the CMPIV provided a high level of freedom from ATAs at late follow-up. Moreover, the CMPIV was equally effective in patients with both paroxysmal and nonparoxysmal $\mathrm{AF}$, and in patients undergoing both standalone and concomitant $\mathrm{AF}$ ablation procedures. The only predictors of late recurrence were duration of preoperative $\mathrm{AF}$ and hospital length of stay.

Our 5-year results were consistent with the good early and midterm results of the CMPIV. ${ }^{4,26}$ In patients receiving a complete lesion set, our 5-year freedom from ATAs was 93 of $119(78 \%)$; freedom from ATAs, without AADs, was 77 of $177(66 \%)$. In the only other study to report late outcomes of the CMPIV, Ad and colleagues ${ }^{17}$ demonstrated that 5 -year freedom from ATAs was $85 \%$, and freedom from ATAs without AADs was
$71 \%$ in a group of 120 patients. The higher percentages in their results may be explained by the fact that their study population had a much shorter median duration of preoperative AF (27 months), compared with that in our study cohort (42 months). As we demonstrated in the present study, preoperative AF duration is an important predictor of late failure, and their freedom from ATAs was consistent with our calculated probability curves (Figure 5).

Our results compare favorably to 2 recent multiinstitutional trials that both showed $66 \%$ freedom from AF, at only the 9 or 12 months' follow-up. ${ }^{27,28}$ However, these studies did not have standardized ablation techniques and included institutions that had variable amounts of experience with surgical ablation. 


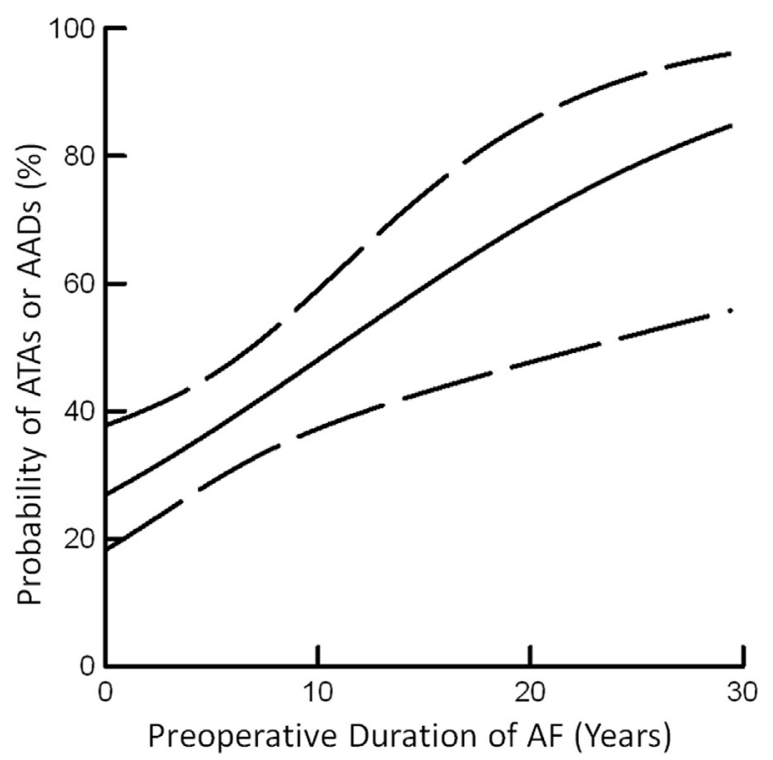

FIGURE 5. Relationship between preoperative AF duration and the probability of ATA recurrence or AAD use at 5-year follow-up. ATA, Atrial tachyarrhythmia; $A A D$, antiarrhythmia drug; $A F$, atrial fibrillation.

The CMPIV results in our series were better than what has been achieved with catheter ablation. In a study ${ }^{23}$ of 100 patients with mainly paroxysmal $\mathrm{AF}$ who underwent catheter ablation, the arrhythmia-free survival after a single ablation procedure was only $29 \%$ at 5 years. Allowing for multiple catheter ablations improved the arrhythmiafree survival, compared with the preceding intervention, to $63 \%$ at 5 years, with a median of 2 procedures per patient. Scherr and colleagues ${ }^{21}$ evaluated arrhythmia-free survival at 5 years for patients that underwent catheter ablation for persistent AF, which was most of the patients in our study. In that study, 150 patients underwent catheter ablation, and the 5-year single procedure success was $17 \%$. Several other large studies evaluating 5 -year success rates after catheter ablation have equally poor results. ${ }^{18,20,22}$ As a comparison to these studies, our data demonstrated 5-year freedom from ATAs of 78\% from a single procedure.

Our results compared favorably to other surgical lesion sets, in particular, pulmonary vein isolation. In a study of 139 patients who underwent minimally invasive surgical pulmonary vein isolation, with up to 5 years of follow-up, freedom from $\mathrm{AF}$, without $\mathrm{AADs}$, was $52 \%, 28 \%$, and $29 \%$ for paroxysmal, persistent, and longstanding persistent $\mathrm{AF}$, respectively. ${ }^{16}$ This finding is consistent with those of other studies indicating that surgical pulmonary vein isolation might be more effective in patients with paroxysmal AF than persistent or longstanding persistent AF. ${ }^{19,29}$ In contrast, our data and those from others ${ }^{14,17}$ have demonstrated that the CMPIV is equally effective in all groups of patients at both early and late follow-up. The consistent efficacy of the CMPIV in nonparoxysmal AF is impressive in light of the worse substrate of $\mathrm{AF}$ in this group, as indicated by the longer duration of preoperative $\mathrm{AF}$, increased left atrial size, and a higher number of failed catheter ablations.

The success of the CMPIV in the concomitant setting is of equal importance considering that most surgical ablations in the United States are performed as part of concomitant cardiac procedures. ${ }^{30}$ Our long-term results are consistent with early and midterm results, both from our institution and others, that have documented high rates of restoration of sinus rhythm with concomitant procedures, including coronary artery bypass, mitral valve surgery, and aortic valve surgery. ${ }^{5-10}$ These data reinforce our belief that the CMPIV should be considered in all patients with AF who are undergoing concomitant cardiac surgery, as long as it can be performed without adding morbidity to the procedure.

This study identified several risk factors for recurrent ATAs by multivariate linear regression models at 1 and 5 years. At 1 year, left atrial size, preoperative pacemaker implantation, and the absence of a box lesion set were predictive of failure, which is consistent with previous studies from our group and others. ${ }^{31-34}$ These variables were not predictors of failure at 5 years: In a recent report from Ad and colleagues, ${ }^{17}$ predictors of recurrence were left atrial size at 2 years and left atrial size, age, and length of hospital stay at 5 years. These inconsistencies suggest the possibility of different underlying pathophysiologic mechanisms of failure at different time points.

The duration of preoperative $\mathrm{AF}$ and the length of hospital stay were both independent predictors of failure at 5 years. Duration of preoperative AF has been shown to predict late recurrence after both catheter and surgical ablation at 5 years in previous studies. ${ }^{17,21,35}$ This finding is likely due to the substrate remodeling that occurs with AF. In patients with long duration of preoperative $\mathrm{AF}$, this remodeling may not be reversible, and the CMP works poorly in this subgroup, particularly in patients with AF for $>11$ years, for whom success rates at 5-year follow-up were $<50 \%$. Hospital length of stay is likely a marker of more underlying comorbidities, which could contribute to late failure.

\section{Limitations}

The success rates were reported for both the biatrial CMPIV and the left-sided CMPIV combined. The leftsided CMPIV lesion set was included in the analysis because the success rates were observed to be similar to that of the biatrial CMPIV. However, this group of patients was highly selected. In our center, a left-sided CMPIV was chosen for patients with paroxysmal AF, left atrial size $<5.0 \mathrm{~cm}$, and no evidence of right atrial enlargement. In this selected group, late efficacy was good; however, comparisons with 
the biatrial CMPIV were not possible because of the limited number of patients available for late follow-up.

This study was retrospective and nonrandomized, which introduced confounding factors that may have affected the results. Incomplete follow-up and not universal continuous cardiac monitoring could have led to overestimation of the freedom results. Additionally, the groups with paroxysmal and nonparoxysmal $\mathrm{AF}$, as well as patients who underwent standalone versus concomitant procedures, were inherently different, making comparisons less than ideal. However, the series included a large number of patients, and the conclusions that the CMPIV works well for all groups is valid and clear. Given that this study was conducted at a single institution, these outcomes may not be obtainable at lessexperienced centers.

\section{CONCLUSIONS}

The CMPIV remains the most successful surgical treatment for AF, even in patients with nonparoxysmal AF and regardless of the complexity of the concomitant procedures. The duration of preoperative AF predicted failure at 5 years, and suggests the need for earlier intervention. Further follow-up of this patient cohort is needed to determine whether a further decrement in success will occur over time.

\section{Conflict of Interest Statement}

RJD receives research grants and educational funding from AtriCure and Edwards Lifesciences. All other authors have nothing to disclose with regard to commercial support.

You can watch a Webcast of this AATS meeting presentation by going to: http://webcast.aats.org/2015/Video/ Monday/04-27-15_4E_1615_Lancaster.mp4

\section{References}

1. Cox JL, Schuessler RB, D'Agostino HJ Jr, Stone CM, Chang BC, Cain ME, et al. The surgical treatment of atrial fibrillation. III. Development of a definitive surgical procedure. J Thorac Cardiovasc Surg. 1991;101:569-83.

2. Weimar T, Bailey MS, Watanabe Y, Marin D, Maniar HS, Schuessler RB, et al. The Cox-maze IV procedure for lone atrial fibrillation: a single center experience in 100 consecutive patients. J Interv Card Electrophysiol. 2011;31:47-54.

3. Gaynor SL, Diodato MD, Prasad SM, Ishii Y, Schuessler RB, Bailey MS, et al. A prospective, single-center clinical trial of a modified Cox maze procedure with bipolar radiofrequency ablation. J Thorac Cardiovasc Surg. 2004;128:535-42.

4. Weimar T, Schena S, Bailey MS, Maniar HS, Schuessler RB, Cox JL, et al. The Cox-maze procedure for lone atrial fibrillation: a single-center experience over 2 decades. Circ Arrhythm Electrophysiol. 2012;5:8-14.

5. Henn MC, Lawrance CP, Sinn LA, Miller JR, Schuessler RB, Moon MR, et al. Effectiveness of surgical ablation in patients with atrial fibrillation and aortic valve disease. Ann Thorac Surg. 2015. pii: S0003-4975(15)00618-9. [Epub ahead of print].

6. Ad N, Holmes SD, Massimiano PS, Pritchard G, Stone LE, Henry L. The effect of the Cox-maze procedure for atrial fibrillation concomitant to mitral and tricuspid valve surgery. J Thorac Cardiovasc Surg. 2013;146: 1426-34; discussion 1434-25.

7. Damiano RJ Jr, Gaynor SL, Bailey M, Prasad S, Cox JL, Boineau JP, et al. The long-term outcome of patients with coronary disease and atrial fibrillation undergoing the Cox maze procedure. J Thorac Cardiovasc Surg. 2003;126:2016-21.

8. Prasad SM, Maniar HS, Camillo CJ, Schuessler RB, Boineau JP, Sundt TM III, et al. The Cox maze III procedure for atrial fibrillation: long-term efficacy in pa- tients undergoing lone versus concomitant procedures. J Thorac Cardiovasc Surg. 2003;126:1822-8.

9. Saint LL, Bailey MS, Prasad S, Guthrie TJ, Bell J, Moon MR, et al. Cox-Maze IV results for patients with lone atrial fibrillation versus concomitant mitral disease Ann Thorac Surg. 2012;93:789-94; discussion 794-5.

10. Stulak JM, Sundt TM III, Dearani JA, Daly RC, Orsulak TA, Schaff HV. Ten-year experience with the Cox-maze procedure for atrial fibrillation: How do we define success? Ann Thorac Surg. 2007;83:1319-24.

11. Robertson JO, Saint LL, Leidenfrost JE, Damiano RJ Jr. Illustrated techniques for performing the Cox-maze IV procedure through a right mini-thoracotomy. Ann Cardiothorac Surg. 2014;3:105-16.

12. Saint LL, Lawrance CP, Leidenfrost JE, Robertson JO, Damiano RJ Jr. How I do it: minimally invasive Cox-maze IV procedure. Ann Cardiothorac Surg. 2014;3: $117-9$.

13. Lawrance CP, Henn MC, Miller JR, Sinn LA, Schuessler RB, Maniar HS, et al. A minimally invasive Cox maze IV procedure is as effective as sternotomy while decreasing major morbidity and hospital stay. J Thorac Cardiovasc Surg. 2014;148:955-61; discussion 962.

14. Ad N, Henry L, Friehling T, Wish M, Holmes SD. Minimally invasive standalone Cox-maze procedure for patients with nonparoxysmal atrial fibrillation. Ann Thorac Surg. 2013;96:792-8; discussion 798-9.

15. Boersma LV, Castella M, van Boven W, Berruezo A, Yilmaz A, Nadal M, et al. Atrial fibrillation catheter ablation versus surgical ablation treatment (FAST): a 2-center randomized clinical trial. Circulation. 2012;125:23-30.

16. Zheng S, Li Y, Han J, Zhang H, Zeng W, Xu C, et al. Long-term results of a minimally invasive surgical pulmonary vein isolation and ganglionic plexi ablation for atrial fibrillation. PLoS One. 2013;8:e79755.

17. Ad N, Holmes SD, Stone LE, Pritchard G, Henry L. Rhythm course over 5 years following surgical ablation for atrial fibrillation. Eur J Cardiothorac Surg. 2015; 47:52-8; discussion 58

18. Bunch TJ, May HT, Bair TL, Jacobs V, Crandall BG, Cutler M, et al. Fiveyear outcomes of catheter ablation in patients with atrial fibrillation and left ventricular systolic dysfunction. J Cardiovasc Electrophysiol. 2014;26: 363-70.

19. De Maat GE, Pozzoli A, Scholten MF, Van Gelder IC, Blaauw Y, Mulder BA, et al. Long-term results of surgical minimally invasive pulmonary vein isolation for paroxysmal lone atrial fibrillation. Europace. 2015;17:747-52.

20. Ganesan AN, Shipp NJ, Brooks AG, Kuklik P, Lau DH, Lim HS, et al. Long-term outcomes of catheter ablation of atrial fibrillation: a systematic review and metaanalysis. J Am Heart Assoc. 2013;2:e004549.

21. Scherr D, Khairy P, Miyazaki S, Aurillac-Lavignolle V, Pascale P, Wilton SB, et al. Five-year outcome of catheter ablation of persistent atrial fibrillation using termination of atrial fibrillation as a procedural endpoint. Circ Arrhythm Electrophysiol. 2015;8:18-24.

22. Schreiber D, Rostock T, Frohlich M, Sultan A, Servatius H, Hoffmann BA, et al. Five-year follow-up after catheter ablation of persistent atrial fibrillation using the stepwise approach and prognostic factors for success. Circ Arrhythm Electrophysiol. 2015;8:306-17.

23. Weerasooriya R, Khairy P, Litalien J, Macle L, Hocini M, Sacher F, et al. Catheter ablation for atrial fibrillation: are results maintained at 5 years of follow-up? $J$ AmColl Cardiol. 2011;57:160-6.

24. Voeller RK, Bailey MS, Zierer A, Lall SC, Sakamoto S, Aubuchon K, et al. Isolating the entire posterior left atrium improves surgical outcomes after the Cox maze procedure. J Thorac Cardiovasc Surg. 2008;135:870-7.

25. Calkins H, Kuck KH, Cappato R, Brugada J, Camm AJ, Chen SA, et al. 2012 HRS/EHRA/ECAS expert consensus statement on catheter and surgical ablation of atrial fibrillation: recommendations for patient selection, procedural techniques, patient management and follow-up, definitions, endpoints, and research trial design: a report of the Heart Rhythm Society (HRS) Task Force on Catheter and Surgical Ablation of Atrial Fibrillation. Heart Rhythm. 2012;9:632-96.e621.

26. Je HG, Shuman DJ, Ad N. A systematic review of minimally invasive surgical treatment for atrial fibrillation: a comparison of the Cox-Maze procedure, beating-heart epicardial ablation, and the hybrid procedure on safety and efficacy. Eur J Cardiothorac Surg. 2015;48:515.

27. Damiano RJ Jr, Badhwar V, Acker MA, Veeragandham RS, Kress DC, Robertson JO, et al. The CURE-AF trial: a prospective, multicenter trial of irrigated radiofrequency ablation for the treatment of persistent atrial fibrillation during concomitant cardiac surgery. Heart Rhythm. 2014;11:39-45.

28. Gillinov AM, Gelijns AC, Parides MK, DeRose JJ Jr, Moskowitz AJ, Voisine P, et al. Surgical ablation of atrial fibrillation during mitral-valve surgery. $N$ Engl J Med. 2015;372:1399-409. 
29. Edgerton JR, Edgerton ZJ, Weaver T, Reed K, Prince S, Herbert MA, et al. Minimally invasive pulmonary vein isolation and partial autonomic denervation for surgical treatment of atrial fibrillation. Ann Thorac Surg. 2008;86:35-8; discussion 39.

30. Ad N, Suri RM, Gammie JS, Sheng S, O'Brien SM, Henry L. Surgical ablation of atrial fibrillation trends and outcomes in North America. J Thorac Cardiovas Surg. 2012;144:1051-60.

31. Lawrance CP, Henn MC, Miller JR, Sinn LA, Schuessler RB, Damiano RJ Jr. Comparison of the stand-alone Cox-Maze IV procedure to the concomitant Cox-Maze IV and mitral valve procedure for atrial fibrillation. Ann Cardiothorac Surg. 2014;3:55-61.

32. Gillinov AM, Sirak J, Blackstone EH, McCarthy PM, Rajeswaran J, Pettersson G, et al. The Cox maze procedure in mitral valve disease: predictors of recurrent atrial fibrillation. J Thorac Cardiovasc Surg. 2005;130:1653-60.

33. Damiano RJ Jr, Schwartz FH, Bailey MS, Maniar HS, Munfakh NA, Moon MR, et al. The Cox maze IV procedure: predictors of late recurrence. J Thor Cardiovasc Surg. 2011;141:113-21.

34. Ad N, Henry L, Holmes SD, Stone LE, Hunt S. The association between early atrial arrhythmia and long-term return to sinus rhythm for patients following the Cox maze procedure for atrial fibrillation. Eur J Cardiothorac Surg. 2013; 44:295-300; discussion 300-291.

35. Gaynor SL, Schuessler RB, Bailey MS, Ishii Y, Boineau JP, Gleva MJ, et al. Surgical treatment of atrial fibrillation: predictors of late recurrence. J Thorac Cardiovasc Surg. 2005;129:104-11.

Key Words: atrial fibrillation, arrhythmia therapy, ablation

\section{Discussion}

Dr Richard Lee (St. Louis, Mo). I would like to thank the society for the opportunity to discuss this article. I have 3 questions. I will ask them sequentially. Dr Damiano and colleagues again set the bar for success with a success rate in excess of $90 \%$ at 1 year for freedom from $\mathrm{AF}$ in this group. In contrast, in a recently randomized prospective study published in the New England Journal of Medicine, by Gillinov et al, the success rate was only $63 \%$ at 1 year, with no difference between biatrial maze and pulmonary vein isolation alone. CURE-AF and ABLATEAF, both prospective, multi-institution studies, also had rates that hovered between $65 \%$ and $70 \%$. How do you reconcile the difference between your results and the others?

Dr Lancaster. Thank you, Dr Lee, and it is a pleasure to have you review our work. We are a high-volume center for AF ablation, and we have multiple decades of experience with this lesion set. Both the Cox maze III and IV lesion sets were developed at our institution. The results that we present here are similar to those reported by other centers, including Niv Ad's group in Virginia, who just published their 5-year results, as well as the group at Northwestern.

The recent multi-institutional trials that you mention, the CURE-AF trial and Dr Gillinov's recent New England Journal of Medicine publication, reported notably worse results than ours, both showing less than $70 \%$ freedom from $\mathrm{AF}$ for the biatrial maze at only 9 or 12 months of follow-up. I do not have a good explanation for this discrepancy, other than that these were multiinstitutional experiences that may have included centers with variable amounts of experience with surgical ablation. For instance, in the CURE-AF trial, in which we participated, the range in freedom from $\mathrm{AF}$ at 9 months of follow-up for the individual participating institutions varied from $33 \%$ to $100 \%$. So obviously, there was a large amount of variability in the results at different institutions.

This is a complex lesion set that is dependent on surgeon experience and consistent completion of the full lesion set. We think that it is translatable to the surgical population at large, but even in our center, where both lesion sets were developed, we still have a $20 \%$ to $30 \%$ rate of treatment failure at long-term follow-up. So there is still room for improvement.

Dr Lee. Although the authors report a benefit of a complete box lesion, it was not an independent predictor of failure at year 5. Please explain why you think it was not, and the potential implications. As you know, the reason why we stopped doing the superior lesion was to increase atrial contractility. In fact, even in the group that did not have a box lesion, about 33\% more were free of AF. So essentially, is there any patient that you think might benefit from a "nonbox" lesion to preserve atrial contraction?

Dr Lancaster. The absence of a complete posterior left atrial box lesion (nonbox) was analyzed as a predictor of ATA recurrence, and it was found to be a significant predictor in univariate analysis at both 1 and 5 years of follow-up. In the multivariate analysis, it was only a significant predictor in the 1-year model, not the 5-year model. However, the difference in freedom from ATAs at 5 years in the non-box lesion group was notably inferior (66\% freedom without AADs in the box lesion group, and only $33 \%$ freedom in the nonbox group). It is likely that if we had a larger number of patients with a non-box lesion set available at late follow-up, this would have been a significant predictor of failure. However, we stopped performing the non-box lesion set in 2005 because of concerns about its efficacy.

At the present time, there is no patient in whom we would consider not performing a box lesion. It is true that the original maze IV lesion set was designed to minimize any compromise to left atrial function that might occur with complete electrical isolation of the posterior left atrium. However, we have demonstrated in magnetic resonance imaging studies that the posterior left atrium actually moves very little during atrial contraction, so any potential compromise that may occur is likely minimal. Additionally, the impact of having a 70\% risk of treatment failure with a nonbox lesion, with those patients who fail remaining in a state with $\mathrm{AF}$, without the benefit of atrioventricular 
synchrony, would most certainly have a greater effect on impaired cardiac output than any potential compromise to left atrial function.

Dr Lee. For my last question - with the advent of new technology, a myriad of lesion sets have evolved over the past decade or so. When the term "mini maze" was popularized, the authors wisely and vocally directed us to use the term maze only for a complete biatrial lesion set, and to label others as AF procedures.

In this maze series, the authors included a traditional biatrial lesion set, a biatrial lesion set minus the superior lesion, as well as left side-only lesions. So now, in 2015, what should and can we call a maze?

Dr Lancaster. As I said earlier, we now consider the left atrial superior connecting lesion to be an essential component of the CMPIV lesion set. We no longer consider the patients that had a nonbox lesion to accurately represent the CMPIV.

We did in this series include 44 patients who had only a left atrial CMPIV. Their lesion set was identical to the left atrial lesion set of the biatrial CMPIV; however, they did not undergo right atrial ablation. This was, however, a highly selected group of patients who had a left atrial size less than $4 \mathrm{~cm}$, paroxysmal $\mathrm{AF}$, and no evidence of right atrial enlargement or tricuspid valve pathology by echocardiography. We decided to include those patients in this study because there was no significant difference in their late outcomes, compared with the biatrial patients. Having said that, only 9 patients in the left atrial group had follow-up at 5 years, and so we are not able to comment on the broader applicability of a left atrialonly versus biatrial CMPIV.

Our policy is to perform a biatrial CMPIV, as we have indicated in published results multiple times, in most patients, unless it is contraindicated. Going forward, the challenge is to define the mechanisms of $\mathrm{AF}$ in the individual patient. With better mechanistic information, it is certain that a left atrial lesion set alone could be appropriate in some patients. Until we have better diagnostic capability, a biatrial lesion set is still our preferred approach.

Dr John Puskas (New York, NY). Dr Lancaster-I know that your mentor, Dr Damiano, has done a lot of work in the laboratory and in the operating room documenting transmurality of lesions for the CMPIV, with different energy sources, for instance, and applying them multiple times, for instance. I wonder if you could tell us how these lesions of the CMPIV were created in this series, and I wonder if Dr Lee could tell us if that is the same way it was done in the other series that you cited that had lower success rates?

Dr Lancaster. In the CMPIV lesion set, as I showed in the illustration, there is a single right atrial incision and a single left atrial incision, and the remainder of the ablation lesions are made with either a bipolar radiofrequency clamp or cryothermal ablation. The bulk of the lesions are made with the bipolar radiofrequency clamp, and cryoablation in our practice is used for the lesions near the mitral valve and tricuspid valve annuli.

Dr Puskas. And are the radiofrequency clamps applied twice, three times, once? How should we be doing them?

Dr Lancaster. Three applications of the clamp: a central application, and then 1 application on either side. We confirm exit block from the pulmonary veins in every patient.

Dr Puskas. So it is applying the clamp 3 times and confirming block. Is that an explanation, Richard?

Dr Lee. Well, it could be. Obviously the other studies did not necessarily require a block. In addition, ABLATE-AF was almost exactly the same. For CURE$\mathrm{AF}$, they used a unipolar pen instead of cryoablation for the mitral annular lesion. For the New England Journal of Medicine article, a combination of lesions and technologies were used, particularly for the mitral annular lesion. So that might account for some of the variability, but it is still a surprise to be that disparate, especially given the high success rates of pulmonary vein isolation alone reported in some series of paroxysmal patients.

Dr Alexandr Bogachev-Prokophiev (Novosibirsk, Russia).

I would like to thank you for these interesting data. You have in your analysis more than 100 patients with a minimally invasive approach. Did you find any differences between the conventional and minimally invasive approach in $\mathrm{AF}$ freedom?

Dr Lancaster. We did not do that analysis in this study, but we have previously published results showing that there was no difference in up to 2-year freedom from $\mathrm{AF}$ between patients that underwent the CMPIV by either a minimally invasive or a standard sternotomy approach.

Dr Harold Roberts (Aventura, Fla).

One short comment and a question. As far as the comment, I think this paper further and again illustrates the fact that it is incumbent for us as surgeons to indefinitely follow our patients after ablation, because the results can and do deteriorate with time.

As far as the question I had, I do not know if this is a chicken-or-egg type scenario, but you had distinctly worse freedom from AF in your patients that were off antiarrhythmics. Was this predominantly because they were off antiarrhythmics, or was it the fact that the cardiologist had just given up?

Dr Lancaster. We reported both overall freedom from ATAs (including patients who are on and off AADs), and freedom from ATAs in patients not taking AADs. In our institutional experience, we have very little control over which patients are taking AADs postoperatively, because many of our 
patients are referred from out of town and from long distances and choose to continue follow-up with their local cardiologist. So some patients continue to take or are told to resume taking AADs without our input. This does raise the point about whether or not we should be relying on that 1 outcome, freedom from ATAs without AADs, as the single benchmark for success, because it may not accurately reflect the success of the procedure. Our practice is to also report overall freedom from ATAs, which may be a more relevant measure of procedural success.

Dr James Edgerton (Dallas, Tex). I would like to make a comment, if I may. I will echo the statement that was just made about following your patients long term. If you are going to do arrhythmia surgery, you really need to adopt a disease management approach to your care, rather than a proceduralist approach.

But I want to answer something that you said about the lesion creation. In my own personal series, every lesion we put on the atrium, we tested for block, by creating an activation sequence of the atrium. And one of the things we are hindered by, as surgeons, is that we do the lesion, we test it, and we move on, because we have got to keep moving, and we cannot get back to that later; or if you are under cardioplegia, you cannot test it at all.

During our hybrid experience doing hybrids in the same day, I would do my procedure, check my lesions for block; everything was blocked. The electrophysiologist was getting to this 3 hours later, checking my lesions and calling me, and saying, Jimmy, you do not have block.

What we learned from that is that we were getting temporary block from the edema, the crushing nature of the clamp; and we had to move the application of the clamp from 3 to 4 applications up to 7 to 8 applications for every line before we consistently had block when he tested them 3 or 4 hours later.

So that may have significant implications for the earlier studies that were done. Thank you.

Dr Puskas. Were those dry or irrigated clamps, Jimmy?

Dr Edgerton. Well, what you are really talking about is cooling, and that was the AtriCure clamp that cools by a different mechanism as a pair of electrodes and they alternate electrodes. So in essence, a cooled lesion is what you are looking for.

Dr Puskas. Can you respond to that question?

Dr Lancaster. This may be a theoretical advantage of the hybrid approach, in that the continuity of surgical ablation lesions can be tested in the operating room or electrophysiology laboratory immediately after the procedure. It will be very interesting to see what the significance of this advantage is in improving the long-term outcomes of hybrid procedures. Unfortunately, these data are not available yet.

Dr Takashi Nitta (Tokyo, Japan), I have a question about the box lesion versus nonbox lesion, particularly about the reason for the different outcome, because I also did a similar analysis and did not see any difference in AF recurrence between the box lesion and the nonbox lesion.

There would be 2 possibilities for the better results after the box lesion in your data. First, your patients frequently had abnormal activations arising from the posterior left atrium that can be encircled by the box lesion. But according to our mapping data, only $4 \%$ of the patients showed that type of abnormal activations from the posterior left atrium.

The other possibility for the different results could be incomplete ablation of the pulmonary vein isolation in the non-box lesion cohort.

What do you think about the reason for the different results?

Dr Lancaster. I might add a third possibility to your suggestions, which is that achieving a full left atrial box lesion not only serves to isolate ectopic AF drivers located in the posterior left atrium, but may also help to reduce the contiguous surface area of the left atrium below the critical mass necessary to perpetuate AF. In other words, it might help block the reentrant conduction of arrhythmias that originate outside of the posterior left atrium, in addition to isolating AF-originating foci located in the posterior left atrium. In an attempt to address some of those questions, we are pursuing our own atrial mapping studies in patients with AF, and it will be interesting to see how many of our patients have origins of $\mathrm{AF}$ in the posterior left atrium. 
TABLE E1. Concomitant procedures

Procedures in addition to CMP Number of patients, $n(\%$; of 408$)$

Mitral valve \pm tricuspid $206(50)$

$\mathrm{CABG} \pm$ mitral $93(23)$

Aortic valve \pm CABG 57 (14)

Aortic valve + mitral valve 13 (3)

Other 39 (10)

$C M P$, Cox-maze procedure; $C A B G$, coronary artery bypass grafting.

TABLE E2. Preoperative demographics

\begin{tabular}{|c|c|c|c|c|}
\hline Demographic & Overall $^{*}(\mathbf{n}=576)$ & Paroxysmal AF $(n=237)$ & Nonparoxysmal AF $(n=336)$ & $P$ value \\
\hline Age (y) & $64 \pm 12$ & $63 \pm 12$ & $64 \pm 12$ & .737 \\
\hline Male & $351(61)$ & $133(56)$ & $217(65)$ & .041 \\
\hline Persistent AF & $66(11)$ & N/A & $66(20)$ & N/A \\
\hline Longstanding persistent $\mathrm{AF}$ & $270(47)$ & N/A & $270(80)$ & N/A \\
\hline Preoperative duration of $\mathrm{AF}(\mathrm{y})$ & $5.8 \pm 6.9$ & $4.9 \pm 7.1$ & $6.6 \pm 6.8$ & .005 \\
\hline Left atrial size $(\mathrm{cm})$ & $5.2 \pm 1.1$ & $5.0 \pm 1.1$ & $5.3 \pm 1.1$ & .006 \\
\hline Failed catheter ablation & $117(20)$ & $22(9)$ & $95(28)$ & $<.001$ \\
\hline Preoperative pacemaker & $73(13)$ & $30(13)$ & $43(13)$ & .961 \\
\hline NYHA class III or IV & $337(59)$ & $134(57)$ & $202(60)$ & .392 \\
\hline $\operatorname{LVEF}(\%)$ & $54 \pm 12$ & $55 \pm 12$ & $53 \pm 12$ & .092 \\
\hline PVD & $63(11)$ & $23(10)$ & $40(12)$ & .407 \\
\hline Hypertension & $378(66)$ & $148(62)$ & $227(68)$ & .205 \\
\hline Dyslipidemia & $337(59)$ & $134(57)$ & $200(60)$ & .476 \\
\hline Chronic lung disease (moderate to severe) & $31(5)$ & $9(4)$ & $22(7)$ & .152 \\
\hline Diabetes & $108(19)$ & $45(19)$ & $63(19)$ & .943 \\
\hline Renal failure & $21(4)$ & $10(3)$ & $11(3)$ & .553 \\
\hline Dialysis & $4(1)$ & $1(0)$ & $3(1)$ & .505 \\
\hline
\end{tabular}

Values are $\mathrm{n}(\%)$, or mean $\pm \mathrm{SD}$, unless otherwise indicated. $A F$, Atrial fibrillation; $N / A$, not applicable; $N Y H A$, New York Heart Association; $L V E F$, left ventricular ejection fraction; $P V D$, peripheral vascular disease. *Includes 3 patients with large atria but no preoperative $\mathrm{AF}$ who underwent ablation at the time of a concomitant procedure. 
TABLE E3. Perioperative data

\begin{tabular}{|c|c|c|c|c|}
\hline Demographic & Overall $*(n=576)$ & Paroxysmal AF $(n=237)$ & Nonparoxysmal AF $(n=336)$ & $P$ value \\
\hline Sternotomy $\dagger$ & $357(79)$ & $182(77)$ & $273(81)$ & .194 \\
\hline Concomitant procedure & $408(71)$ & $193(81)$ & $212(63)$ & $<.001$ \\
\hline CPB time (min) & $174 \pm 47$ & $182 \pm 46$ & $171 \pm 48$ & .004 \\
\hline Crossclamp time (min) & $83 \pm 35$ & $90 \pm 32$ & $78 \pm 36$ & $<.001$ \\
\hline Box lesion & $509(88)$ & $204(86)$ & $305(91)$ & .079 \\
\hline Early atrial tachyarrhythmias & $325(56)$ & $132(56)$ & $193(57)$ & .678 \\
\hline ICU length of stay (d) & $4.7 \pm 6.5$ & $5.0 \pm 6.1$ & $4.6 \pm 6.8$ & .579 \\
\hline Hospital length of stay (d) & $12 \pm 10$ & $12 \pm 9$ & $12 \pm 10$ & .607 \\
\hline 30-d mortality & $17(3)$ & $4(2)$ & $13(4)$ & .142 \\
\hline Postoperative permanent pacemaker & $70(12)$ & $36(15)$ & $34(10)$ & .068 \\
\hline Major complications & $90(16)$ & $42(18)$ & $48(14)$ & .266 \\
\hline Renal failure (dialysis) & $25(4)$ & $12(5)$ & $13(4)$ & .491 \\
\hline Myocardial infarction & $1(0)$ & $0(0)$ & $1(0)$ & .401 \\
\hline Stroke & $7(1)$ & $5(2)$ & $2(1)$ & .104 \\
\hline Mediastinitis & $2(0)$ & $2(1)$ & $0(0)$ & .092 \\
\hline Reoperation for bleeding & $25(4)$ & $12(5)$ & $13(4)$ & .491 \\
\hline Pneumonia & $49(9)$ & $27(11)$ & $22(7)$ & .041 \\
\hline Intra-aortic balloon pump & $16(3)$ & $4(2)$ & $12(4)$ & .178 \\
\hline
\end{tabular}

Values are $\mathrm{n}(\%)$, or mean $\pm \mathrm{SD}$, unless otherwise indicated. $A F$, Atrial fibrillation; $C P B$, cardiopulmonary bypass; $I C U$, intensive care unit. *Includes 3 patients with large atria but no preoperative $\mathrm{AF}$ who underwent ablation at the time of a concomitant procedure. $\nmid$ All patients who did not undergo sternotomy underwent right minithoracotomy.

TABLE E4. Variables predicting atrial tachyarrhythmia recurrence by univariate analysis

\begin{tabular}{lcc}
\hline \multicolumn{1}{c}{ Variable } & $\begin{array}{r}\boldsymbol{P} \text { value } \\
\text { (at 1 y) }\end{array}$ & $\begin{array}{r}\boldsymbol{P} \text { value } \\
\text { (at 5 y) }\end{array}$ \\
\hline No box lesion & $<.001$ & .008 \\
Early atrial tachyarrhythmia & .001 & .013 \\
Preoperative duration of atrial fibrillation & .568 & .010 \\
Left atrial size & .002 & .547 \\
Preoperative pacemaker & .003 & .070 \\
Overall major complications & 1.000 & .045 \\
Intensive care unit length of stay & .797 & .035 \\
Hospital length of stay & .723 & .009 \\
\hline
\end{tabular}

